\title{
Percutaneous closure of a patent foramen ovale after cryptogenic stroke
}

\author{
R. J. R. Snijder ${ }^{1}$ M. J. Suttorp ${ }^{1}$ J. M. ten Berg ${ }^{1}$ - M. C. Post ${ }^{1}$
}

Published online: 4 December 2017

(c) The Author(s) 2017. This article is an open access publication.

\begin{abstract}
A patent foramen ovale is a common intracardiac finding that is located between the left and right atrium. It can cause right-to-left shunting and has a high prevalence in patients who suffer a cryptogenic stroke. Earlier trials did not show superiority of percutaneous patent foramen ovale closure with standard medical therapy over standard medical therapy alone in the treatment of cryptogenic stroke. Interestingly, several meta-analyses show positive results regarding closure, suggesting underpowering of the individual trials. Recently, two large prospective trials and one long-term follow-up study showed benefit of percutaneous closure over standard medical therapy in treatment of cryptogenic stroke. A larger right-to-left shunt or the presence of an atrial septal aneurysm were predictors for a recurrent event. Therefore, percutaneous patent foramen ovale closure after cryptogenic stroke should be recommended over antiplatelet therapy alone in patients younger than 55 years of age with a high-risk patent foramen ovale.
\end{abstract}

Keywords Patent foramen ovale $\cdot$ Percutaneous PFO closure $\cdot$ Stroke

\section{Introduction}

Patent foramen ovale (PFO) is a common intracardiac finding that is located between the left and right atrium and is found in about $25 \%$ of the population. In patients with cryptogenic stroke or transient ischaemic attack (TIA) the prevalence rises to $50 \%$ [1].

Large case-control studies showed an association between PFO and cryptogenic stroke, especially in patients younger than 55 years of age [2]. Several observational studies described a reduction in recurrent neurological events after percutaneous PFO closure with standard medical therapy (later mentioned as percutaneous PFO closure) compared with lifelong medical therapy [3, 4]. A few years ago, three prospective randomised trials failed to show superiority of percutaneous PFO closure. Long-term followup was lacking though. These trials differ in patient selection and type of device used [5-7]. However, several metaanalyses showed a benefit of percutaneous PFO closure suggesting underpowering of the individual studies $[8,9]$. Recently, two large randomised controlled trials and one

R. J. R. Snijder

rj.snijder@antoniusziekenhuis.nl

1 Department of Cardiology, St. Antonius Hospital, Nieuwegein, The Netherlands long-term follow-up study of an earlier trial were published. We discuss these trials in this point of view article and give our recommendation about the optimal treatment for cryptogenic stroke in the presence of a PFO.

\section{Earlier trials: clinical outcome and predictors for recurrence of stroke}

Three prospective randomised trials have been published studying the difference between medical therapy and percutaneous PFO closure in patients who suffered from a cryptogenic stroke or TIA. A summary of these trials is shown in Tab. 1.

The first trial, CLOSURE-1 ('Evaluation of the STARFlex Septal Closure System in Patients with a Stroke and/or Transient Ischemic Attack due to Presumed Paradoxical Embolism through a Patent Foramen Ovale'), was published in 2012 and included 909 patients who presented with a cryptogenic stroke or TIA. At least a moderate rightto-left shunt (RLS) or an atrial septal aneurysm (ASA) was present in $52.9 \%$ and $36.6 \%$, respectively. The STARFlex device (NMT Medicals) plus antiplatelet therapy (clopidogrel for 6 months and aspirin for 2 years) were used in the closure group and oral anticoagulation (OAC), aspirin or both in the medical therapy group at the discretion of the principal investigator. The primary endpoint, the composite 
Table 1 Study characteristics of the CLOSURE-1, PC, RESPECT, Gore REDUCE and CLOSE trials

\begin{tabular}{|c|c|c|c|c|c|}
\hline & CLOSURE-1 & $\mathrm{PC}$ & RESPECT & $\begin{array}{l}\text { Gore RE- } \\
\text { DUCE }\end{array}$ & CLOSE \\
\hline Patients $(n)$ & 909 & 414 & 980 & 664 & 663 \\
\hline Mean age (years) & $45.9 \pm 9.5$ & $44.5 \pm 10.1$ & $45.9 \pm 9.9$ & $45.2 \pm 9.4$ & $43.3 \pm 10.4$ \\
\hline Male $(\%)$ & 51.8 & 49.8 & 54.7 & 60.1 & 58.9 \\
\hline $\begin{array}{l}\text { Moderate or large RLS } \\
(\%)\end{array}$ & 52.9 & 65.6 & 75.2 & 81.3 & 100.0 \\
\hline $\operatorname{ASA}(\%)$ & 36.6 & 23.7 & 35.6 & $20.4^{\mathrm{a}}$ & 32.8 \\
\hline \multicolumn{6}{|l|}{ Treatment } \\
\hline Type of medical therapy & Aspirin, OAC or both & $\begin{array}{l}\text { Antiplatelet, OAC or } \\
\text { both }\end{array}$ & Antiplatelet or OAC & Antiplatelet & $\begin{array}{l}\text { Antiplatelet } \\
\text { or OAC }\end{array}$ \\
\hline Oral anticoagulation (\%) & 34.0 & 31.0 & 25.0 & 0.0 & 28.2 \\
\hline Type of closure device & STARFlex & Amplatzer PFO & Amplatzer PFO & $\begin{array}{l}\text { Helex sep- } \\
\text { tal occluder/ } \\
\text { Cardioform } \\
\text { septal occluder }\end{array}$ & $\begin{array}{l}\text { Any ICC-ap- } \\
\text { proved device }\end{array}$ \\
\hline \multicolumn{6}{|l|}{ Follow-up } \\
\hline $\begin{array}{l}\text { Mean follow-up time } \\
\text { (months) }\end{array}$ & 44.0 & 49.0 & 31.0 & 38.4 & 63.6 \\
\hline Effective closure (\%) & 86.1 & 95.9 & 93.5 & 75.6 & 93.0 \\
\hline $\begin{array}{l}\text { Drop-out medical therapy } \\
(\%)\end{array}$ & 0.87 & 15.2 & 17.2 & 14.8 & 5.1 \\
\hline $\begin{array}{l}\text { Drop-out closure device } \\
(\%)\end{array}$ & 10.1 & 3.9 & 9.2 & 8.8 & 8.8 \\
\hline \multicolumn{6}{|c|}{ Adverse events medical therapy } \\
\hline Major bleeding (\%) & 1.1 & 1.4 & 1.9 & 2.7 & 2.1 \\
\hline Atrial fibrillation (\%) & 0.7 & 1.0 & 1.5 & 0.4 & 0.9 \\
\hline \multicolumn{6}{|l|}{ Adverse events closure device } \\
\hline $\begin{array}{l}\text { Major procedural compli- } \\
\text { cation }(\%)\end{array}$ & 3.2 & 1.5 & 0.6 & 2.5 & 5.9 \\
\hline $\begin{array}{l}\text { Non-procedural major } \\
\text { bleeding }(\%)\end{array}$ & 2.6 & 0.5 & 1.6 & 0.9 & 0.8 \\
\hline Atrial fibrillation (\%) & 5.7 & 2.9 & 3.0 & 6.6 & 4.6 \\
\hline \multicolumn{6}{|l|}{ Endpoints medical therapy } \\
\hline Stroke $(\%)$ & 3.1 & 2.4 & 3.3 & 5.4 & 6.0 \\
\hline TIA $(\%)$ & 4.1 & 3.3 & - & - & - \\
\hline Death $(\%)$ & 0.0 & 0.0 & 1.2 & 0.0 & 0.0 \\
\hline \multicolumn{6}{|l|}{ Endpoints closure device } \\
\hline Stroke $(\%)$ & 2.9 & 0.5 & 1.8 & 1.4 & 0.0 \\
\hline TIA $(\%)$ & 3.1 & 2.5 & - & - & - \\
\hline Death $(\%)$ & 0.0 & 1.0 & 0.6 & 0.5 & 0 \\
\hline Conclusion & $\begin{array}{l}\text { No significant benefit } \\
\text { for closure }\end{array}$ & $\begin{array}{l}\text { No significant benefit } \\
\text { for closure }\end{array}$ & $\begin{array}{l}\text { No significant benefit } \\
\text { for closure }\end{array}$ & $\begin{array}{l}\text { Significant } \\
\text { benefit for } \\
\text { closure }\end{array}$ & $\begin{array}{l}\text { Significant } \\
\text { benefit for } \\
\text { closure }\end{array}$ \\
\hline
\end{tabular}

$A S A$ atrial septal aneurysm, ICC Interventional Cardiology Committee, $O A C$ oral anticoagulation, $P F O$ patent foramen ovale, $R L S$ right-to-left-shunt, TIA transient ischaemic attack

${ }^{\mathrm{a} A S A}$ was only measured in CD group

of stroke/TIA during 2-year follow-up, death from any cause during the first 30 days, and death from neurologic cause between 31 days and 2 years, was reached in $5.5 \%$ after closure and in $6.8 \%$ in the medical therapy group (adjusted hazard ratio (HR), 0.78; 95\% confidence interval
(CI), 0.45-1.35; $p=0.37$ ). Subgroup analysis showed no predictors for recurrent stroke/TIA [5].

The PC trial ('Using the Amplatzer PFO Occluder with Medical Treatment in Patients with Cryptogenic Embolism') was published in 2013 and included 414 patients who suffered a cryptogenic stroke, TIA or a peripheral 


\title{
Advertisement placed here.
}

\author{
SCS bohn \\ stafleu \\ CL van loghum \\ Springer Media
}

Houten 2018 


\title{
Advertisement placed here.
}

\author{
SCS bohn \\ stafleu \\ CL van loghum \\ Springer Media
}

Houten 2018 
thromboembolic event. At least a moderate RLS was present in $65.6 \%$ and an ASA in 23.7\%. The closure group received an Amplatzer device (St. Jude Medical), clopidogrel for 1-6 months and aspirin for at least 6 months. Medical therapy consisted of antiplatelet therapy, OAC, or both, at the discretion of the treating physician. During mean follow-up of 4.0 years, the primary endpoint (composite of death, non-fatal stroke, TIA or peripheral embolism) occurred after closure and after medical therapy, in 3.4\% and $5.2 \%$, respectively (HR $0.63,95 \%$ CI: $0.24-1.62 ; p=$ 0.34 ). Subgroup analysis found no predictors for recurrent stroke/TIA [6].

Finally, the RESPECT trial ('Randomised Evaluation of Recurrent Stroke Comparing PFO Closure to Established Current Standard of Care Treatment'), published in 2013, randomised 980 patients with cryptogenic stroke to closure (Amplatzer device, St. Jude Medical, plus aspirin and clopidogrel for 1 month, followed by aspirin alone for 5 months) or to medical therapy (aspirin, clopidogrel or warfarin). At least a moderate RLS was present in $75.2 \%$ and an ASA in $35.6 \%$. After a mean follow-up of 2.6 years, the primary endpoint (composite of recurrent fatal and non-fatal ischaemic stroke, death from any cause within 30 days after implantation or 45 days after randomisation) was reached in the closure and medical therapy group in $3.4 \%$ and $5.2 \%$, respectively (HR 0.49, 95\% CI: $0.22-1.11 ; p=0.08$ ). Subgroup analysis showed a benefit for closure in presence of larger RLS (HR 0.18, 95\% CI: $0.04-0.81 ; p=0.01$ ) or ASA (HR 0.19, 95\% CI: 0.04-0.87; $p=0.02$ ) [7].

None of these three trials showed superiority of percutaneous closure over medical therapy. However, the trials had study limitations and are difficult to compare. Firstly, the dropout rate was high, based on crossover to closure. Secondly, different devices were used for percutaneous closure. The CLOSURE-1 trial used the STARFlex device, which is already off the market due to poorer efficacy and safety data. Both the PC and the RESPECT trial used the Amplatzer device, which has proven to be safe and effective. Thirdly, different primary endpoints were used: the CLOSURE-1 and PC trials used stroke and TIA as endpoint, the RESPECT trial only stroke. Patient selection was different between trials. For instance, the CLOSURE-1 trial included patients without a proven stroke on imaging, where the PC trial also included patients with a peripheral embolism. Long-term medical therapy was different between trials as well, based on physicians' preference. Finally, all trials had a modest statistical power with a relatively small population and low clinical event rates.

Even though PFO closure was at least equal in comparison to medical therapy, it did not change the guidelines or clinical practice.

\section{Meta-analyses and review}

Several meta-analyses were published discussing these trials mentioned above, including a total of 2,303 patients.

Khan et al. suggest that PFO closure is beneficial when compared with medical therapy in the prevention of recurrent stroke. The effect-estimate HR was 0.67 (95\% CI: $0.44-1.00 ; p=0.05)$ in the intention-to-treat, $0.62(95 \% \mathrm{CI}$ : $0.40-0.95 ; p=0.03)$ using per-protocol, and 0.61 (95\% CI: $0.40-0.95 ; p=0.03$ ) using the as-treated cohort, all showing a beneficial effect for PFO closure. After pooling the results of the trials using the Amplatzer device, the results showed an even more positive effect for PFO closure (HR 0.54, 95\% CI: $0.29-1.01 ; p=0.05$ ) [8].

Rengifo-Moreno et al. defined primary outcome as a recurrent stroke and/or TIA and found a significant risk reduction after PFO closure (pooled HR 0.59, 95\% CI: 0.36-0.97; $p=0.04$ ). The composite outcome of death, neurological events and peripheral embolism based on intention-totreat analyses showed a possible benefit for closure (pooled HR $0.67,95 \%$ CI: $0.44-1.00 ; p=0.05$ ). A substantial RLS at baseline tended to be associated with a decrease in vascular events after closure (pooled HR $0.35,95 \% \mathrm{CI}$ : $0.12-1.03 ; p=0.06$ ) [9].

There were also meta-analyses without a statistically significant difference between closure and medical therapy. Ntaios et al. and Kwong et al. showed no significant difference in recurrent stroke between closure and medical therapy (odds ratio (OR) $0.64, p=0.11$ and OR $0.65, p=0.17$, respectively). Furthermore, there was no difference in the occurrence of TIA or death between both treatment arms. Subgroup analyses showed a possible benefit on stroke rate for percutaneous closure using the Amplatzer PFO occluder (OR $0.46, p=0.04$ and OR $0.47, p=0.06$, respectively) $[10,11]$. And finally, a review by $\mathrm{Li}$ et al. showed no statistically significant difference in recurrent stroke or TIA between closure and medical therapy (relatively risk 0.73 ; 95\% CI: 0.45-1.17) [12].

The meta-analyses described above showed similar complications, mainly vascular complications and atrial fibrillation. The complications were significantly higher after closure.

\section{Recent trials}

Recently, two large randomised trials and one long-term follow-up study of the earlier described RESPECT trial were published [13-15]. A summary of these trials is shown in Tab. 1.

The Gore REDUCE trial ('GORE HELEX Septal Occluder/GORE CARDIOFORM Septal Occluder for Patent Foramen Ovale Closure in Stroke Patients') randomised 
664 patients in a 2:1 ratio to percutaneous closure (Helex septal occluder/Cardioform septal occluder, W.L. Gore and Associates) plus antiplatelet therapy or antiplatelet therapy alone. The co-primary endpoints were freedom from clinical evidence of ischaemic stroke and incidence of new brain infarction, which was a composite of clinical ischaemic stroke or silent brain infarction detected on imaging, both 24 months after randomisation. At least a moderate RLS was present in $81.3 \%$ and an ASA in $20.4 \%$. During a median follow-up of 3.2 years, stroke occurred after closure and after medical therapy in $1.4 \%$ and $5.4 \%$, respectively (HR 0.23 ; 95\% CI: $0.09-0.62 ; p=0.002$ ). New brain infarctions were found in $5.7 \%$ and $11.3 \%$, respectively (HR 0.51 ; 95\% CI: $0.29-0.91 ; p=0.04)$. A significant benefit for closure was found in patients having a substantial RLS (HR 0.18 ; 95\% CI: $0.06-0.58 ; p=0.001)$. Atrial fibrillation occurred significantly more often in the closure group $(p<$ $0.001)$. However, there was no significant difference in the overall serious adverse events $(p=0.22)$ [13].

The CLOSE trial ('Patent Foramen Ovale Closure or Anticoagulants Versus Antiplatelet Therapy to Prevent Stroke Recurrence') assigned 663 patients who recently suffered a stroke in the presence of high-risk PFO (large RLS or ASA) in a 1:1:1 ratio to percutaneous PFO closure plus long-term antiplatelet therapy, antiplatelet therapy alone or OAC alone. At least a moderate RLS was present in $100 \%$ and an ASA in $32.8 \%$. During a mean follow-up of 5.3 years, the primary endpoint (occurrence of stroke) was reached in $0 \%$ in the closure group, in $6.0 \%$ in the antiplatelet group (HR 0.03; 95\% CI: $0-0.26 ; p=<0.001$ ), and $1.6 \%$ in the OAC group. This study was not powered to compare the outcome between antiplatelet therapy and OAC. Closure-related events occurred in 5.9\%. There was no significant difference in serious adverse events between both treatment arms $(p=0.56)$. Onset of atrial fibrillation occurred significantly more often after closure $(p=0.02)$ [14].

The previously described RESPECT trial published data with an extended median follow-up of 5.9 years. The number of patients and the primary endpoint are described above. The two groups were not equal at the latest follow-up due to a high dropout rate $(33.3 \%)$ in the medically treated group. Recurrent non-fatal stroke occurred in $3.6 \%$ ( 0.58 events per 100 patient-years) after closure and in $5.8 \%$ (1.07 events per 100 patient-years) receiving medical therapy (HR $0.55 ; 95 \%$ CI: $0.31-0.999 ; p=0.046$ ). Subgroup analysis showed a benefit for closure in presence of a substantial RLS (HR 0.26; 95\% CI: $0.10-0.71 ; p=$ 0.005 ) or ASA (HR 0.20; 95\% CI: $0.06-0.70 ; p=0.005$ ). Both serious adverse events and atrial fibrillation did not significantly differ between both groups [15].

In summary, the two recent trials and the extended follow-up study showed a significant benefit for percuta- neous PFO closure when compared with medical therapy alone (especially antiplatelet therapy) in younger patients who suffer a cryptogenic stroke. This beneficial effect was greater in patients with a high-risk PFO (defined as a PFO with a at least a moderate RLS and/or ASA).

The difference between the earlier and recent trials could be explained by the fact that recent trials were more uniform, had a long-term follow-up and a different endpoint compared with earlier trials. More importantly, recent trials included patients with at least a moderate RLS and/or an ASA, which are known as high-risk PFOs, and showed an even greater effect of closure.

\section{How to decide which PFO to close?}

In the past, literature did not reach consensus in which symptomatic patient group the PFO should be closed. The latest ESC guidelines describe a class IIa level of evidence $\mathrm{C}$ for percutaneous PFO closure in young patients with a systemic paradoxical embolism [16]. The 2017 Dutch guideline acknowledges the potential benefit for percutaneous PFO closure in selected patients; class IIa level of evidence A [17].

Age and presence of atherosclerosis play an important role in whether PFO is a likely cause of cryptogenic stroke. Pezzini et al. showed that with lesser risk factors for atherosclerosis, the influence of PFO increases [18]. Kent et al. created a calculator to stratify the likelihood of PFO related to stroke [19]. The Risk of Paradoxical Embolism (RoPE) calculator uses important risk factors for atherosclerosis (hypertension, diabetes, history of stroke or TIA and smoking), the presence of a cortical infarct on imaging and age for identifying a PFO related stroke. The higher the RoPE score (between 0 and 10 points), the more likely a PFO is related to stroke. Using a multivariate model after inclusion of more than 3,000 patients, younger age and the absence of risk factors mentioned above were found to be associated with the presence of a PFO related stroke. The optimal cut-off value to identify a strokerelated PFO was a RoPE score of at least 6. However, presence of a large shunt or ASA was not included even though previous studies have shown an association between cryptogenic stroke and these high-risk PFOs [20]. Using echocardiography, ASA is defined as more than $10 \mathrm{~mm}$ bulging of the atrial septum and the severity of a RLS is calculated on the maximum amount of bubbles in the left atrium, and graded as minimal, moderate or large [21, 22]. In contrast to the CLOSURE-1 and PC trial, the earlier RESPECT trial found a significant benefit for closure in presence of a large RLS or ASA. The more recent studies (Gore REDUCE and RESPECT) found a large RLS or ASA as predictors for benefit of PFO closure. Moreover, 


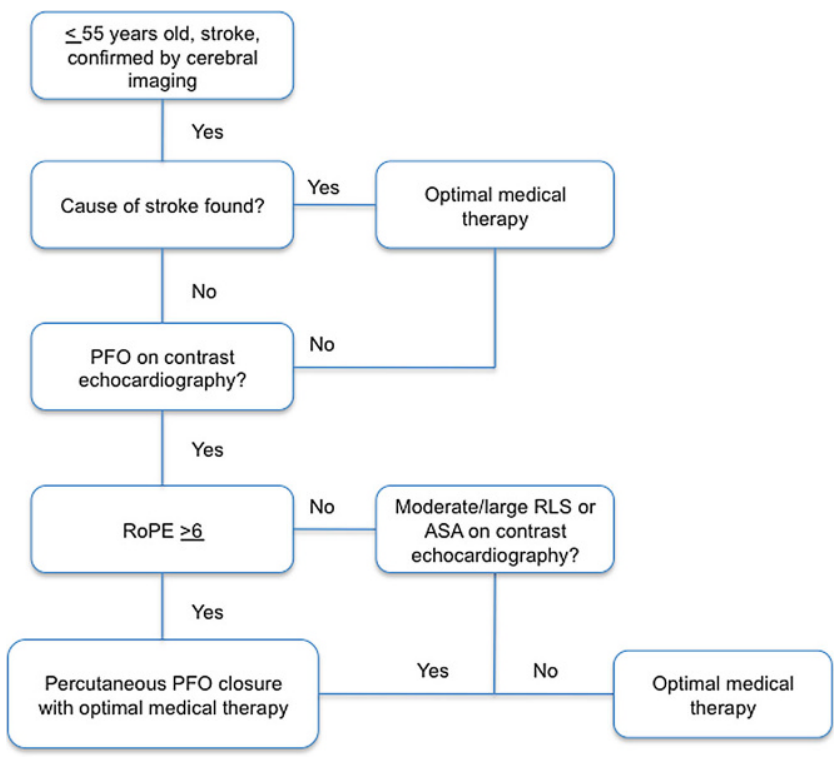

Fig. 1 Algorithm for the treatment of cryptogenic stroke. ASA atrial septal aneurysm, $P F O$ patent foramen ovale, $R L S$ right-to-left shunt, $R o P E$ risk of paradoxical embolism

the CLOSE trial only included patients with these PFO characteristics and showed an overall significant, positive effect for closure. The difference in significance between the earlier and recent trials could be explained by the limitations of the earlier trials.

Therefore, after exclusion of other possible causes, percutaneous PFO closure using a safe and effective device in combination with medical therapy should be recommended over medical therapy alone in young patients $(\leq 55$ years of age) who suffer a cryptogenic stroke confirmed by cerebral imaging. A RoPE score of at least 6 or a high-risk (at least moderate RLS or ASA) PFO should be present. Adverse events of PFO closure should be taken into account. A recent study including more than 1,800 percutaneous PFO closure procedures showed a complication rate of $4.9 \%$ in patients younger than 60 years of age (mainly vascular complications and paroxysmal atrial fibrillation). This rate is similar when compared with the recent trials [23].

In Fig. 1, we suggest an algorithm for the treatment of cryptogenic stroke in the presence of PFO.

\section{Recommendation}

At this moment, literature shows a significant beneficial effect of percutaneous PFO closure over medical therapy alone in selected patients who suffer a cryptogenic stroke. It is important to exclude other possible causes of stroke before considering percutaneous closure. The RoPE score, described earlier, could be a useful instrument in determin- ing the possible association between stroke and the presence of a PFO, but the score might underestimate the risk. It has become clear that the presence of a significant RLS or an ASA are important discriminators to determine whether a stroke is related to a PFO. Based on the currently available literature, the current guidelines should be updated in favour of percutaneous PFO closure in young patients who suffer a cryptogenic stroke. The RoPE score and the presence of a high-risk PFO should be important factors to guide the decision.

\section{Conclusion}

Percutaneous PFO closure should be the recommended treatment over medical therapy in young patients suffering cryptogenic stroke.

Conflict of interest R.J.R. Snijder, M.J. Suttorp, J.M. ten Berg and M.C. Post declare that they have no competing interests.

Open Access This article is distributed under the terms of the Creative Commons Attribution 4.0 International License (http:// creativecommons.org/licenses/by/4.0/), which permits unrestricted use, distribution, and reproduction in any medium, provided you give appropriate credit to the original author(s) and the source, provide a link to the Creative Commons license, and indicate if changes were made.

\section{References}

1. Overell JR, Bone I, Lees KR. Interatrial septal abnormalities and stroke: a meta-analysis of case-control studies. Neurology. 2000;55:1172-9.

2. Handke $M$, et al. Patent foramen ovale and cryptogenic stroke in older patients. N Engl J Med. 2007;357:2262-8.

3. Windecker S, Wahl A, Chatterjee T, et al. Percutaneous closure of patent foramen ovale in patients with paradoxical embolism: long-term risk of recurrent thromboembolic events. Circulation. 2000;101:893-8.

4. Post MC, Van Deyk K, Budts W. Percutaneous closure of a patent foramen ovale: Single-centre experience using different types of devices and mid-term outcome. Acta Cardiol. 2005;60:515-9.

5. Furlan AJ, Reisman M, Massaro J, et al. Closure or medical therapy for cryptogenic stroke with patent foramen ovale. N Engl J Med. 2012;366:991-9.

6. Meier B, Kalesan B, Mattle HP, et al. Percutaneous closure of patent foramen ovale in cryptogenic embolism. N Engl $\mathrm{J}$ Med. 2013;368:1083-91.

7. Carrol JD, Saver JL, Thaler DE, et al. Closure of patent foramen ovale versus medical therapy after cryptogenic stroke. N Engl J Med. 2013;368:1092-100.

8. Khan AR, Aref A, Abdulhak B, et al. Device closure of patent foramen ovale versus medical therapy in cryptogenic stroke. A systematic review and meta-analysis. JACC Cardiovasc Interv. 2013;6:1316-23.

9. Rengifo-Moreno P, Palacios IF, Junpaparp P, Witzke CF, Morris DL, Romero-Corral A. Patent foramen ovale transcatheter closure vs. medical therapy on recurrent vascular events: a systematic review and meta-analysis of randomized controlled trials. Eur Heart J. 2013;34:3342-52. 
10. Ntaios G, Papavasileiou V, Makaritsis K, Michel P. PFO closure vs. medical therapy in cryptogenic stroke or transient ischemic attack: A systemic review and meta-analysis. Int J Cardiol. 2013;169:101-5.

11. Kwong JS, Lam YY, Yu CM. Percutaneous closure of patent foramen ovale for cryptogenic stroke: a meta-analysis of randomized controlled trials. Int J Cardiol. 2013;168:4132-8.

12. Li J, Liu J, Liu M, Zhang S, Hao Z, Zhang J, Zhang C. Closure versus medical therapy for preventing recurrent stroke in patients with patent foramen ovale and a history of cryptogenic stroke or transient ischemic attack (Review). Cochrane Database Syst Rev. 2015; https://doi.org/10.1002/14651858.CD009938.pub2.

13. Sondergaard L, et al. Patent foramen ovale closure or antiplatelet therapy for cryptogenic stroke. N Eng J Med. 2017;377:1033-42.

14. Mas JL, et al. Patent foramen ovale closure or anticoagulation vs. antiplatelets after stroke. N Eng J Med. 2017;377:1011-21.

15. Saver JL, et al. Long-term outcomes of patent foramen ovale closure or medical therapy after stroke. N Eng J Med. 2017;377:102232.

16. Baumgartner, et al. ESC Guidelines for the management of grownup congenital heart disease. Eur Heart J. 2010;31:2915-57.
17. Van Dijk A, et al. Guideline for the closure of patent foramen ovale [internet]. NVVC. 2017. https://www.nvvc.nl/media/richtlijn/208/ 2017_Leidraad_PFO-sluiting.pdf. Accessed 8 Mar 2017

18. Pezzini A, Grassi M, Lodigiani, et al. Interaction between proatherosclerotic factors and right-to-left shunt on the risk of cryptogenic stroke: the Italian Project on Stroke in Young Adults. Heart. 2012;98:485-9.

19. Kent DM, Ruthazer R, Weimar C, et al. An index to identify strokerelated vs incidental patent foramen ovale in cryptogenic stroke. Neurology. 2013;81:619-25.

20. Snijder RJ, et al. Patent foramen ovale with atrial septal aneurysm is strongly associated with migraine with aura: a large observational study. J Am Heart Assoc. 2016;5(12):e3771.

21. Mugge A, Daniel WG, Angermann C, et al. Atrial septal aneurysm in adult patients: a multicenter study using transthoracic and transesophageal echocardiography. Circulation. 1995;91:2785-92.

22. Velthuis S, Buscarini E, Gossage JR, Snijder RJ, Mager JJ, Post MC. Clinical implications of pulmonary shunting on saline contrast echocardiography. J Am Soc Echocardiogr. 2015;28:255-63.

23. Merkler AE, Gialdini G, Yaghi S, et al. Safety outcomes after percutaneous transcatheter closure of patent foramen ovale. Stroke. 2017;48:3073-7. 